Así como los tres últimos llevan un escudo, que refleja el ser pieza de encargo, los nuestros llevan una pequeña cartela de metal dorado rodeada de coral. La comparación sobre todo con los de la colección belga permite conocer exactamente como eran las chapas que ornaban no solo los frentes, sino también la caja del mueble, prácticamente desaparecidas en los de Guadalupe ${ }^{13}$.

La ornamentación en coral y plata dorada o bronce, tuvo su principal centro de producción seicentista en Palermo, de cuyos talleres proceden la mayoría de las piezas conservadas desde la década de los cuarenta ${ }^{14}$, fecha que parece coincidir estilísticamente con la de los dos escritorios, de proporciones regulares y distribución sencilla, muy en consonancia con los que se realizan en Napoles en ébano y marfil. En los talleres granducales por esos mismos años se decoran los escritorios con placas de mármoles y piedras duras. El liderazgo florentino es reconocido en toda Europa, pero la producción se extiende a otros talleres, no necesariamente de la propia Galería, incluso a otras ciudades, como Nápoles, adonde llegaron los diseños de Ligozzi y otros, combinándose con una decoración propia siciliana como es el coral. No son muy habituales en la manufactura de los artistas granducales estas imágenes de animales silueteados sobre un fondo de paragone, prefiriendose los pájaros y las flores, pero bien pudieron hacerse las placas en Florencia y llevarse en conjunto para montar en los frentes de los muebles, o haberse realizado en Nápoles por artistas toscanos allí establecidos como fue, entre otros, Domenico Montini, el maestro senés que realizó el tabernáculo de Felipe III ya que no es raro encontrar en inventarios españoles escritorios decorados «con payses en piedra de Nápoles» ${ }^{15}$.

María PAZ AgUiló

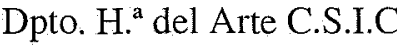

\title{
LOS RELIEVES DE BACANALES QUE DECORABAN EL ALCÁZAR *
}

Ya teníamos noticias por Bellori, de los regalos que el Cardenal Barberini hizo llegar a la corte española, y sobre los que ahora, podemos hacer alguna precisión. Se señala en la edición moderna de la obra de Bellori, que el biógrafo equivoca el relieve que acabó en el Alcázar madrileño, ya que la obra citada como copia de Tomaso Fedele en pórfido, siguiendo el

lote 204 , de donde parece pasó a la colección española. Las placas están montadas en una caja mucho más grande sobre pies con soportes antropomórficos, basados en I Cinque Libri di Architectura de Montano editados en. Roma en 1684 que inspiraron el grabado de Pierre Gole «Les cabinets de la Guerre et de la Paix», y atribuido en su arquitectura, a René Chauveau, ebanista casado con la hija de Domenico Cucci, artista florentino director de la Manufactura de los Gobelinos, cfr. C.Demetrescu «Domenico Cucci, le plus baroque des ebenistes de Louis XIV», L'Objet d'Art. n. ${ }^{\circ} 306$. Octubre, 1996, pp. 58-75.

${ }_{13}$ Por su colocación inaccesible en el pequeño reservado del Joyel no se ha podido constatar si los fragmentos que aún consevan son de plata dorada o de bronce.

14 Fernando Martín en el catálogo de plata del Convento de Santa Isabel, rastrea el origen palermitano de piezas allí existentes adelantando su fecha hasta 1645-1647, año en que don Juan de Austria envía a Felipe IV el cuadro de Ribera. Real Fundación del Convento de Santa Isabel de Madrid, 1990, p. 155 y ss.

15 Barrio Moya: «La librería de la dama madrileña Doña María Josefa de Cuéllar y Losa (1704), Anales del Instituto de Estudios Madrileños, 1996, p. 415.

\footnotetext{
* Mi agradecimiento a Margarita Estella Marcos, por su ayuda.
} 
diseño de Duquesnoy no es la que indica, sino el bajorrelieve que atribuye directamente a su mano, sin indicar el material «Figuro l'Amor divino che abbatte l'Amor profano calcandolo col piede e chiudendogli la bocca con la mano per farlo tacere, mentre un altro fanciullo inalza la corona di lauro un premio della vittoria immortale» ${ }^{1}$. Sobre esta obra, la copia hecha en pórfido por Fedele sobre el diseño del amor divino y el amor profano de Duquesnoy aportaremos algún nuevo dato, sobre su venida a España y su colocación, y también sobre una Bacanal de putti en bronce de Duquesnoy ${ }^{2}$.

El relieve en pórfido, llamado en los inventarios «Bacanal», actualmente en el Museo del Prado ${ }^{3}$ con el $n .^{\circ} 300$, se ha puesto siempre en relación con el n. ${ }^{\circ} 297$ relieve realizado en pórfido sobre fondo de mármol amarillo, el «Hércules Niño», desde que los viera ya juntos Ponz, en el nuevo Palacio ${ }^{4}$. También sobre la relación entre ambas obras quisiera hacer alguna reflexión (Figs. 24 y 25).

$\mathrm{Si}$ analizamos los distintos inventarios de Palacio ${ }^{5}$, podemos ver los cambios en la disposición de estos relieves en el antiguo Alcázar, entre el reinado de Felipe IV y el de Carlos II, aunque, como sabemos, los cambios en la decoración escultórica en este edificio en los años a los cuales hacemos referencia, fuesen mínimos ${ }^{6}$. En $1700^{7}$, nos encontramos en el pasillo llamado de la «Madonita» con el $\mathrm{n}^{\circ}{ }^{2} 6$ «un niño hércules en la cuna de cuasi relieve entero de pórfido con las serpientes en la mano embutido en la pared de cerca de una vara en cuadro y de mármol negro jaspeado que se tasó por el dicho Pedro Alonso escultor y por Carlos Gantir marmolista en ocho mil ducados de vellón» que correspondería al n. ${ }^{\circ} 297$ del Museo del Prado. En la Galería de Retratos con los n. ${ }^{\text {os }} 32$ y 33, se inventarian: «Item, un Bacanal de Bronze a manera de cuadro con figura de relieve y el campo de lapislazuli de siete cuartas de ancho y una vara de alto y el marco de bronze tasada por el dicho escultor y por el cotraste y platero en un mil seiscientos y cincuenta doblones de a dos»; «Item, otra bacanal de pórfido de medio relieve que es un juego de quatro niños y tiene siette cuartas de largo y una vara de alto con marco de bronze dorado tasada la medalla en 12.000 ducados de vellón y el marco en un mil y doscientos ducados que todo monta 13.200 ducados que hacen

1 Bellori, G. P.: Le Vite de Pittori Scultori e architetti moderni, 1672. Ed. Giulio Ennandi 1976 a cargo de Evelina Borea, pp. 289-230.

2 Para la obra de Duquesnoy véase: Fransolet, M.: François du Quesnoy Sculpteur d'Urbain VIII. Bruselas, 1941.- Nava Cellini, A.: Duquesnoy, en «I maestri della scultura», n. 83 de Fratelli Fabbri Editori, 1966.Para distintos aspectos sobre su estilo: Freytag, C.: Neuentdeckte Werke des François du Quesnoy. Pantheon, pp. 199-211, Julio-Septiembre, 1976.- Schlegel, U.: Der lenothaph des Jakob von Hase von François Dusquesnoy. Jahrbuch der Berliner Museen der Prenssischen Kunstsaminlungen Neue Folge. Vol. XVIII, 1976, pp. 134-135.

3 Blanco y Llorente: Catálogo de escultura del Museo del Prado, 1969. Ed. 1981, pp. 215-218. Lám. 25.Coppel Areizaga, R.: Catálogo de la escultura de la Época Moderna. Siglos XVI y XVIII. Madrid, 1998. En la p. 128 recoge la comunicación de J. Montagu (1966), según la cual el fundidor del marco fue Giovanni Artusi y el dorador Michele Sprinati.

4 Ponz: Viaje de España, 1772-1794, Tomo IV.

5 Bottineau, Y.: Bulletin Hispanique, 1956 LVIII, n. ${ }^{\circ}$ 4, pp. 421-452; 1958, LX n. 1, pp. 30-61; LX n. $^{\circ}$, pp. 145-179; LX n. ${ }^{\circ}$ 3, pp. 289-326; LX n. ${ }^{\circ}$; pp. 450-483. Recoge los inventarios de 1666, 1686 y 1700.-Fernández Bayton, G.: Inventarios reales. Testamentaría del Rey Carlos II, 1701-1703. Museo del Prado, Madrid, 1975, 2 Vols. Archivo General de Palacio (A.G.P.) Registros. Testamentaría Carlos II n. ${ }^{\circ} 240$, Tomo I.

6 Morán Turina, M.: Las estatuas del Alcázar. Notas sobre las colecciones escultóricas de los Austrias, pp. 248-263. Checa, F.: Las colecciones de pintura en el Alcázar de Madrid durante el siglo XVII. Los inventarios de 1636, 1666, 1686 y 1700. La Galería del Mediodía, pp. 400-402. Estos tres artículos en El Real Alcázar de Madrid. Catálogo de la Exposición, Madrid, 1994.- Orso, S.: Philliph IV and The Decoration of The Alcázar of Madrid. Princeton, 1986, p. 28. Solamente hace mención del inventario de 1666 indicando que había «two cay reliefs of children's bachanals».

7 A.G.P. Registros: Testamentaría Carlos II, n. ${ }^{\circ} 220$, Tomo I, fols. 206r-207v. 
145.200 rs.». Bottineau, al comentar que los adornos no habían variado casi nada, en los años finales de siglo, en este pasillo, indica que el Hércules niño y el bufete, que aparecen en el inventario de 1686, ya estaban recogidos en el inventario de 1666 y volverán a aparecer en el de 1700, pero además añade: «Il y avait en outre "un bacanario de unos niños", en pophyre, sculpté en demi-relief et estimé 6.000 ducats». Siendo así en el año 1666 ambos relieves de pórfido, hoy en el Museo del Prado, se encontrarían en el pasillo de la Madona, y según señala el mismo autor más adelante, en el inventario de 1686, coincidiendo con en el de 1700 , se encuentran las dos Bacanales, la de pórfido y la de bronce ya en la Galería del Mediodía llamada también Galería de los retratos.

Así lo confirman las noticias encontradas entre las cartas que un fiel servidor del Cardenal Barberini le envía a Roma, dándole cuenta del lugar donde se encuentran los regalos que había mandado al rey español. En el año 1667, nos informa que el Bajorrelieve de bronce, está en la Biblioteca a la espera de que se realizase un marco del mismo material.

Obra que no se debe encargar ya que Barberini se encargará de hacer llegar a Madrid un marco que satisfará los deseos reales. Marco que el mismo escribiente ese mismo año llevará al Alcázar, donde verá no sólo la Bacanal de bronce, que de momento se guardó en la biblioteca, a la cual, una vez colocado su marco, se colocará «en el lugar que merece», como le indica Sebastián Herrera Barnuevo, sino también conocerá cómo el otro bajorrelieve de pórfido y los dos Bufetes están en «el paso de la Galería». De ellos, uno decorado con las abejas parece que fue muy utilizado por el rey Felipe.IV, pues aún dos años después de su muerte parece que conservaba las manchas de tinta, que la real pluma dejó en él ${ }^{8}$.

${ }^{8}$ BIBLIOTECA VATICANA. Barberini Lateranensis. n. ${ }^{\circ} 9861$. BIBLIOTECA VATICANA. P. 355v: Madrid 15 set 1667 «ll sud. $\mathrm{P}^{\text {ad. }}$ galeno, ne altra persona mi ha mai avvisato che cosa habbia io a fare della cornice di bronzo che diiessei li mesi passati e della speza che mi ha caosato ne mandei ai y via di barcellona la roba al padre.» / P. 365v: Madrid 28 Septiembre. 1667. «Quanto alla cornice di bronzo. la tett "sud. ${ }^{\text {at }}$ di v. em mene porta il primo avviso, et il padre ant ${ }^{\circ} \mathrm{m}^{\text {. }}$ di negro della comp. ${ }^{a}$ quale con sua lett. ${ }^{2}$ in data de 28 aprele mi incamino da Gen ${ }^{a}$ la cassa sud ${ }^{\text {.a }}$ di ordine del padre Galeno a disposizi. ${ }^{\text {ne }}$ de v. ${ }^{\text {a }}$ em. " non mi invivo lett" alcuna di Roma . Ho fatto su. "la diligenza y visitare il quoadro o sia basso rilievo di bronze et disponer le cose prima di portarmi a pie di che $s$. $\mathrm{m}^{\text {t" }}$ ma perche D. Sebastiano D. Herrera a cui ne tocca l'incombenza sta convalexcente di podayra mi dice che bna ${ }^{\text {venura }}$ eio. ${ }^{\text {na }} \mathrm{mi}$ assistera, et che li pare che all'hora $\mathrm{S} . \mathrm{M}^{\text {ta }}$ lo faccesse riponere nella libraria sino a che si fabricasse una cornice di bronzo a proporzione, peró vederó io le cose, faro quello che di dovra, et ne serviro distintam.te con l'aviso v. ${ }^{\text {emza }}$." / Pág 371: Madrid 5 Noviembre 1667."In data del 29 del caduto mese con l'occs. ${ }^{\text {.me }}$ del straord. ${ }^{\text {nio }}$ speditosi costa dal s.g Cardinale Visconti; ho servito v. ${ }^{\text {em.a }}$ con mia lett." a quanto mi occorressa. Di questa settimana fecci portare a Palazzo le cornize di bronzo ${ }^{p}$ il basso rilievo, e fú entrata la cassa nel salone in tempo che il Re che Dio g. ${ }^{\text {de }}$ assistito da D. Michaela nipote della s. ${ }^{\text {ra }}$ Cont $^{\text {al }}$ di Riela si portava a vedere una carrozza, mmolse che sub ${ }^{\circ}$ si aprisse, et la vidde. D. Sebastiano D Herrera che la ricceviese la fecce esponere in luogo che la Regina la vedesse sicome segni, et poi mi insegno il Basso rilievo, quale sta tuttavia posto sopra una tavola in una stanza di libraria dove si deposito per ordine del Re, che sia in cielo, sino a che si fabricasse una cornice di bronzo, cosi mi dice il $\operatorname{sud}^{\circ} \mathrm{D}$. Sebastiano, et adesso si procurerá darli il luogo che merita. Mi fecce vedere il Basso rilievo di porfido, che sta nel paso della Galeria dove sonl li due ricchissimi buffetti, l'uno de quali arrichito dall'api resta tuttavia macchiato d'inchiostro, occasionato datto scrivere, che li facceva S. $\mathrm{M}^{\text {tat }}$, sicome mi dice il sud. ${ }^{\circ}$ Herrera». / P. 375r: 12 Noviembre 1667. «Lunedi mi presente alli piedi della s. rigina in nome di V. ${ }^{\text {ra }}$ em.", et nella espressione di offerire a S. M.ta con la cornice di bronzo y il basso rilievo dorato, la continna missima memoria di V. em. ${ }^{a}$ in tutte le cose al servitio della corona; S. Mta. con serenis.mo aggradimento rispose due volte, on ora buena. Haveva $S . M^{\text {ta }}$ in mani un guante lavato di quelli che mi ricercó la s.ra Cont.sa che cosi S. cec.a mi suppose havere inteso da D. Michaela sua nipote, quale le ragnag ho ancora, che la Regina haveva veduto la cornice et che le Dame assistenti dissero essere cosi chiara nell oro che non mostrava fosse stata navigata si longamente sub. ${ }^{\circ}$ che io intenderó dove si sará situata lo avisaró a v. ${ }^{\text {thit }} m^{\text {th }}$. 

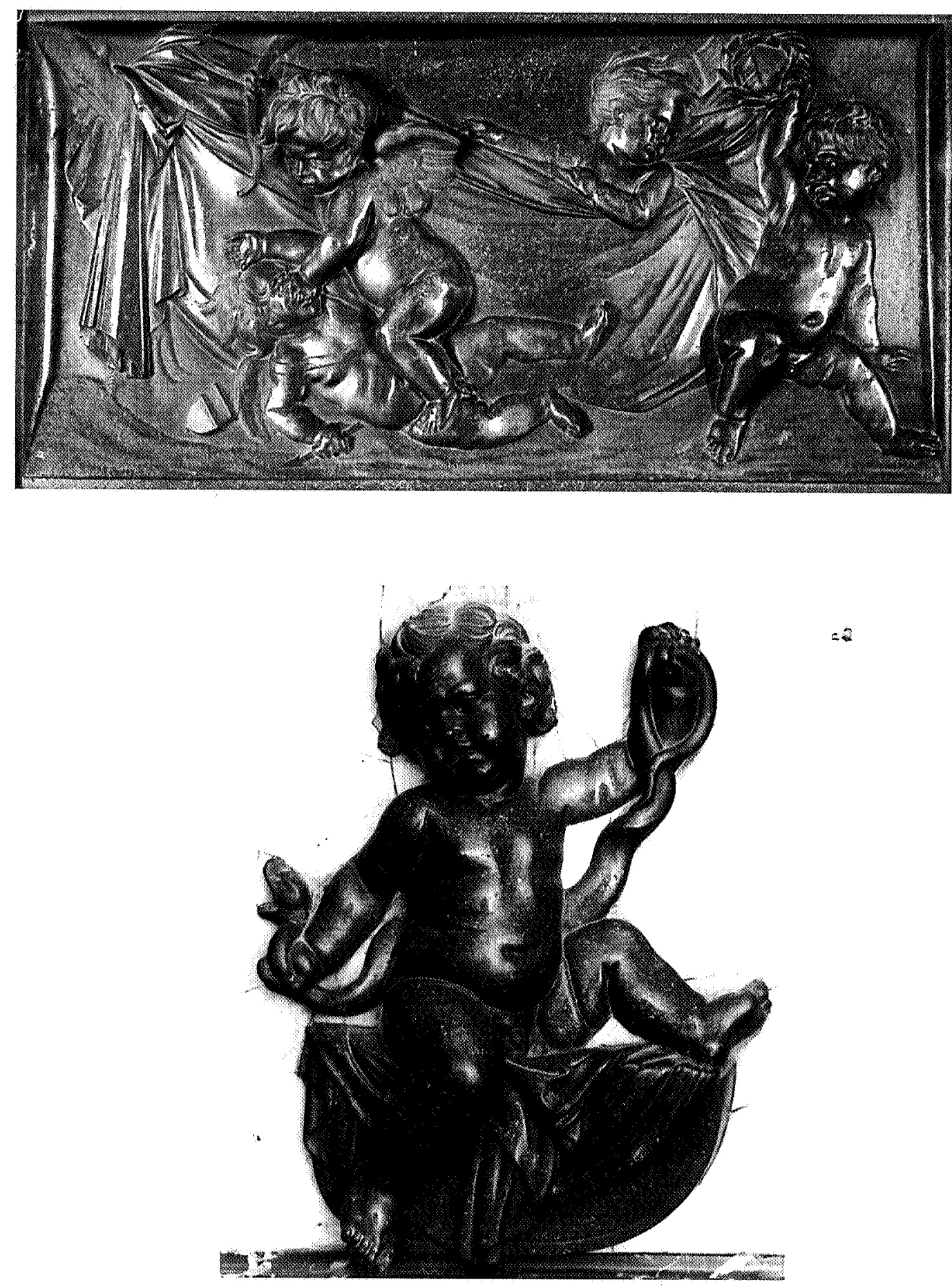

$=2$

Tommaso Fedele: «Del pórfido»: Figura 24. El Amor sagrado venciendo al Amor profano. Madrid. Museo del Prado. Figura 25. Hércules Niño. Madrid. Museo del Prado. 
No desaprovecha el corresponsal la oportunidad, para hacer ver a su señor la diligencia con que realiza su labor, contando como entró el cajón con el marco en palacio en el momento que lo viese el Rey, y las alabanzas que recibió por parte de la reina y de otras damas. Marco trasladado por mar, y que por lo escrito, sufrió pocos desperfectos en el viaje, y que podemos relacionar con el marco también en bronce dorado que tenía el bajorrelieve de pórfido ${ }^{9}$, y que, como hemos visto al citar el inventario de 1700 , fue tasado aparte de la meda1la, gracias a lo cual conocemos su estimable valor. Con las noticias de esta carta, podemos conocer, que el bajorrelieve de la bacanal en bronce, fue ya regalado a Felipe IV, pero que aún dos años después de su muerte está en la biblioteca, a la espera del marco. Pero además nos deja entrever algún dato curioso. Cuando al enviado de Barberini, le muestra Sebastián Herrera Barnuevo dónde estaban los regalos que había enviado a la corte, cita el bajorrelieve de pórfido, y los dos bufetes, pero no habla del otro relieve en pórfido, el del Hércules niño.

En el año 1674, en las fechas en las que se está componiendo el cuarto del rey, tenemos nuevas noticias del mismo corresponsal, con motivo de su visita al Alcázar, nos da a conocer que el bajorrelieve de pórfido que estaba antes en el pasadizo de la sala ochavada, ha sido trasladado a la «Galería de la torrecilla» y encastrado en el muro en correspondencia de la Bacanal de bronce dorado con fondo de lapislázuli. Ambos relieves, se colocaron a los lados de la puerta que daba paso a la alcoba, en la cual se colocaron los dos bufetes, que también fueron regalo del Cardenal, mostrándose así juntos todos los obsequios, y para complacer a su señor el cronista le indica que «nadie como él habia contribuido con tanta grandeza» ${ }^{10}$. De nuevo, como en la carta de 1667, no se cita como regalo de Barberini el Hércules niño, pero aún así, aquí también de nuevo se citan dos bajorrelieves, no solamente el realizado por Tomaso Fedele, el de pórfido, sino también otro realizado en Bronce, disegno del fiamingo, junto con dos Bufetes ${ }^{11}$, también regalados por el Cardenal. Se situaron definitivamente ambas «Bacanales», que podemos identificar por la descripción ya vista del inventario de 1700 , en la puerta que daba paso de la Galería del Mediodía a la alcoba.

Estas noticias, rescatadas del fondo Barberini, concuerdan totalmente con lo señalado en los inventarios y lo recogido por Bottineau: En 1666 aún está la «Bacanal» de pórfido en el pasillo, junto al Hércules niño, donde continúa en 1667, año en el cual vemos que aún está la de bronce en la biblioteca, y en 1674 el bajorrelieve de la «Bacanal» en pórfido, ya se ha trasladado a la Galería del Mediodía, donde se ha situado también la obra de bronce y lapislázuli como se señala en las cartas, y como confirman también los inventarios de 1686 y 1700. La nueva colocación de ambas «bacanales» juntas, a las cuales se añaden los bufetes que también regaló el Cardenal, refuerza la idea de que se quisieran situar todos los regalos en la misma sala, aunque de nuevo no se cuenta con el «Hércules niño». Siempre se ha pues-

9 Véase nota 3: Coppel Areizaga, R., recogiendo la opinión de Montagú, J, sobre los autores del marco.

10 BIBLIOTECA VATICANA. Barberini Lateranensis, n. 9860 . P. $93 \mathrm{v}$ : Madrid 26 Diciembre 1674. «Il s.r Maggiordhuomo Maggiore fá componere á tutta diligenza il quarto del Re, in questa congiuntura sono stato á vederlo, et ho riconosciuto, che il basso rilievo di porfido, che stava prima fabricato nel passadizo della sala ochavada, é stato portato alla galleria della torresilla, et fabricato nella muraglia in corrispondenza dell' altro basso rilievo di bronzo dorato in campo di Lapislazaro, dissegno del fiamingo, et in mezzo sudetti rilievi v'é la porta dell'alcovita, nella quale sono collocati li due buffetti di gioie, si che sono unite tutte é quatro queste super- bissime memorie del generosissimo animo di v. em. ${ }^{\text {za }}$, et é certo, che per quanto questa grande galleria include immense gioie, tutti quanti si trovammo presenti, riconobbimo, che nessuno haveva contribuito di gran linga, con tanta grandezza».

11 Uno de los cuales puede ser el n. ${ }^{\circ} 27$, en el pasillo: «un bufete de pórfido de vara y media de largo y tres cuartas de ancho con sus pies de madera tasado por el dicho Carlos gautier en 4.000 rs». A.G.P. Not. Cit. Fol 206v. En el inventario de 1700, en la Alcoba de la galería, no se recogen los dos bufetes. 
to en relación esta obra con la «Bacanal» de Tomaso Fedele, desde que Ponz las ve juntas, pero ya en el Palacio Nuevo, y cada vez que se toma la cita de Bellori se incluye al Hércules, aunque no se haga referencia directa a él. Me parece extraño, que este relieve que se encontraba ya en 1666 en el Alcázar no sea alabado por el corresponsal como los otros regalos, si tuvo el mismo origen. Además, ya que analizamos los dos relieves, sobre los que se ha señalado que podrían tener su origen ambos en los diseños de Duquesnoy, podemos señalar que el Hércules niño, al igual que la «bacanal» en pórfido, supera las dificultades técnicas que impone el material, por lo cual pudiese ser obra también de Tomaso Fedele, difiere en distintos rasgos del otro relieve, aunque los modelos infantiles de «angelitos gorditos» sea el mismo: Los gestos o las cabelleras, hacen pensar que la procedencia de los diseños que ejecutó para ambas obras, a mi parecer el mismo Tomaso Fedele era distinta.

Otra de las razones, además del origen del regalo, que se podrían señalar para la colocación de ambas «Bacanales» juntas, la podemos encontrar al analizar los temas de ambos relieves y buscar temas similares en la obra del «Fiamingo».

Hemos visto cómo en los inventarios reales, al hablar del relieve de pórfido y del de bronce, sobre campo de lapislázuli, se describen ambos como «Bacanales», siguiendo a los cuales, los he seguido citando así, aunque en realidad se trataría de dos temas distintos: $L a$ Bacanal de pórfido de medio relieve que es un juego de cuatro niños es «el amor divino que abate al amor profano» y Una bacanal de bronce a manera de cuadro con relieve y en campo de lapislázuli, correspondería a una «Bacanal de putti».

Me resulta muy verosímil pensar que estos dos relieves que estaban en el Alcázar fuesen iguales a los de la colección Doria-Pamphilj, ya que así se recrearían las dos «fascinantes invenciones» ${ }^{12}$ de Duquesnoy que se hallaban en la Villa Romana dẻ Belrespiro đế los DoriaPamphilj al Gianicolo.

Del «Amor divino que abate el amor profano», se conocen aparte del relieve Pamphiliano, el modelo en terracota de la Galería Spada, el más vigoroso, el relieve en mármol que se conserva en el Detroit Institute of Arts, de menor calidad y el dibujo de los Uffizi, que Faldi considera posterior, o el dibujo de Andrea Podesta en el British Museum de Londres, aparte del precedente que podemos encontrar en el angelito que sostiene la corona de laurel en el Monumento de Adriano Urybuch en Santa Maria dell'Anima ${ }^{13}$; y de la «Bacanal de Putti» se conocen aparte del mármol mutilado en parte de la Villa Doria-Pamphili, el marfil del Victoria and Albert Museum que nos muestra el diseño completo, y una versión reducida del tema en el mármol de Cracow (Collegium Maius inv. 40/111) ${ }^{14}$. De la mezcla de ambos, resultaría lo que Faldi definió como «gustosissima contaminatio»: la bacanal de putti que se encuentra en la Galleria Borghese de Roma.

Por tanto el pequeño cambio efectuado en la decoración del Alcázar al colocarse juntos ambos relieves, que vendrían a rememorar la decoración de la Villa, contribuiría aún más a mostrar la relación entre ambas obras. Con este planteamiento veríamos que Bellori, sí equivocaría de qué diseño de Duquesnoy realizó la copia en pórfido Fedele, pero estaría en lo cierto cuando señala que «fece un baccanale della medesima grandezza, con putti che tirano per la corna, e sferzano una capra, fuguratovi il Giuoco che e un fanciullo, il quale si pone al

12 Faldi, I.: Le «Virtuose operationi» di Francesco Duquesnoy scultore incomparabile. Arte Antica e Moderna, 5, 1959, pp. 52-62. (Ilustraciones de la Villa: tavole 29a y 29b).

13 Nava Cellini, A.: Op. cit., p. 5.

14 Fabianski, M.: «Studies in Duquesnoy: His litterary sources and imitators». Antichitá Viva, 5-6, 1986, pp. 40-49, 1986. Recoge las opiniones de G. P. Bellori, F. Baldunucci, G. G. Passeri y J. Von Sandrart sobre la importancia de las numerosas copias de Duquesnoy en varias colecciones. 
volto una maschera» ${ }^{15}$, que estaba también presente en las colecciones de Felipe IV como regalo del Cardenal Barberini.

La pequeña descripción y noticias que nos dan las cartas, también pueden aclarar un poco más, al cotejarlos con los inventarios, las obras realizadas en el interior del Alcázar en el reinado de Carlos II, ya que fueron escasas las reformas que se efectuaron en los años finales del siglo, y son pocas las noticias con las que contamos, sobre todo por la dificultad resultante de carecer de planos que expliquen las transformaciones realizadas en el cuarto del rey ${ }^{16}$.

Transformaciones en las cuales podemos señalar la participación de Sebastián Herrera Barnuevo ${ }^{17}$. Aunque él muere en 1672, y por tanto en las cartas de 1674 no se le cita, sí tenemos noticia de su labor en las enviadas a Roma en 1667, donde se le nombra como persona encargada de acomodar el regalo, exponerlo y también será él quien le explique al visitante dónde se situará. Efectivamente, para el año 1667, el polifacético artista ${ }^{18}$, además de tener la plaza de pintor ${ }^{19}$ de cámara, ya se ocupaba en el oficio de la furriera ${ }^{20}$, aunque no llegase a alcanzar el puesto de aposentador ${ }^{21}$, para el cual sí llegó a ser propuesto. No tuvo pues, tanta suerte en alcanzar este cargo, como cuando llegó a ocupar el puesto de maestro mayor, sin haber seguido los «peldaños habituales», que indica Barbeito ${ }^{22}$; pero sí tenemos con esta nota una noticia del papel orientador que pudo jugar en los pequeños cambios efectuados en Alcázar, como asesor, ya que aunque no llegase a ocupar el puesto que obtuvo Velázquez, sí pudo dar consejos, en virtud de su gusto para la redecoración del cuarto del rey.

\section{J JESÚS MUÑOZ GONZÁLEZ}

15 Bellori, G. P.: Op. cit., pp. 289-290.

16 Barbeito, J. M.: El Alcázar de Madrid. Madrid, 1992, pp. 191-196.

17 Palomino, A.: El Museo Pictórico y la escala Óptica. Tomo III: El parnaso español, pintoresco y laureado, 1796. Ed. Aguilar, 1988, pp. 318-321.- Llaguno, A.: Noticias de los arquitectos y de arquitectura en España desde su restauración. Tomo IV. ${ }^{\circ}, 1892$. Ed. 1977, pp. 58-60.

${ }_{18}$ Algunas de sus múltiples actividades se pueden ver en: Blasco Esquivias, B.: La maestría mayor de obras de Madrid a lo largo de su historia, origen, evolución y virtual supresión del empleo. Anales del instituto de Estudios Madrileños. Tomo XXXI, 1992, pp. 509-537.- Bonet Correa, A.: El túmulo de Felipe IV, de Herrera Barnuevo y los retablos baldaquinos del barroco español. Archivo Español de Arte, 1961, pp. 285-296.- Cayetano Martín, M. ${ }^{a}$ C.; Flores Guerrero, P.; Gallego Rubio, C.: Sebastián Herrera Barnuevo, Maestro Mayor de las obras de Madrid (1665-1671). Revista Villa de Madrid. Año XXVII, 1989, I. n. ${ }^{\circ}$ 99, pp. 50-56.- Tovar Martín, V.: Arquitectura Madrileña del siglo XVII, 1983, pp. 101-119.- Wethey, H. E.: Herrera Barnuevo's work for the Jesuits of Madrid, Art Quarterly, XVII, 1954, pp. 335-344; Decorative Projects of Sebastian de Herrera Barnuevo, Burlington Magazine, XCVIII, Febr. 1956, pp. 41-46; Sebastian Herrera Barnuevo, Anales del Instituto de Arte Americano e investigaciones estéticas, Tomo II, 1958, pp. 13-41; Herrera Barnuevo y su capilla de las Descalzas Reales, Reales Sitios, IV, 13, 1967, pp. 12-21.-Zarco Del Valle, M.: Documentos inéḑitos para la historia de bellas artes en España. Madrid, 1870, pp. 234-237.

19 De Azcárate, J. M.a: Algunas noticias sobre pintores cortesanos del siglo XVII. Anales del Instituto de Estudios Madrileños VI, 1970, p. 51.

${ }^{20}$ A.G.P. Expediente Personal de Sebastián Herrera Barnuevo. Caja 507. Expediente 40. En un escrito de 14 de Junio de 1662, se indica: «se descontará a Don Sebastián de Herrera 32.584 mrs. en descuento con la media Anata por la m. ${ }^{\text {rd }}$ que su $\mathrm{M}^{\mathrm{ag}}$ le ha hecho de plaza de ayuda de la furriera de los primeros gajes que hubiere de haver con los dhos off. ${ }^{o s}$...».

21 Zarco Del Valle, M.: Op. cit., 1870, p. 235.

22 Barbeito, J.M.: Op. cit,. 1992, p. 180: «con su nombramiento alteró el rey la costumbre de que el maestro mayor fuera elegido entre personas ya vinculadas a las oras reales». 